\title{
Erratum to: Meiosis, hyperbole, irony
}

\author{
Kendall L. Walton ${ }^{1,2}$
}

Published online: 25 November 2016

(C) Springer Science+Business Media Dordrecht 2016

\section{Erratum to: Philos Stud DOI 10.1007/s11098-015-0546-6}

The original version of this article was published with certain errors that are corrected in this erratum. The final paragraph of Sect. 4 should read as follows:

The salient contrast of

(20) There was a tsunami off the coast of Sumatra this morning (uttered on December 26, 2004).

is that there wasn't a tsunami that morning; the speaker asserts that there was, rather than wasn't, a tsunami on the morning she speaks. But that there was no tsunami needn't previously have been in anyone's consciousness or in any sense in the conversational air. The parties to the conversation (except for the speaker) might not even know what a tsunami is. Once the speaker utters (20), however, it is probably clear that she means especially to be denying that a tsunami did not occur that morning-clear at least that, whatever tsunamis are, she is denying that there wasn't one.

The online version of the original article can be found under doi:10.1007/s11098-015-0546-6.

Kendall L. Walton

klwalton@umich.edu

1 University of Michigan, Ann Arbor, MI, USA

2 Stanford University, Stanford, CA, USA 